\title{
ON THE EFFECTS OF DOMESTICATION ON CANINE SOCIAL DEVELOPMENT AND BEHAVIOR
}

\author{
HARRY FRANK and MARTHA GIALDINI FRANK
}

University of Michigan-Flint, Flint, MI 48503 (U.S.A.)

(Accepted for publication 24 November 1981)

\begin{abstract}
Frank, H. and Frank, M.G., 1982. On the effects of domestication on canine social development and behavior. Appl. Anim. Ethol., 8: 507-525.
\end{abstract}

Social development and behavior are compared for 4 Eastern timber wolves (C. lupus lycaon) and 4 Alaskan Malamutes (C. familiaris). The two groups were born a year apart, but all were fostered at approximately 10 days of age on the same lactating female wolf, reared jointly by the authors and the foster mother, housed in the same facility, and subjected to the same regimen of maintenance and social contact with adult members of the animal colony. It is suggested that many of the observed group differences can be attributed to selection in domestic dogs for prolongation of juvenile behavior and morphological characteristics. Discussion then focuses on the evolution and ontogeny of ritualized aggression in wolves and the effects of domestication on agonistic behavior in domestic dogs. It is suggested that the disintegration of ritualized aggression in dogs is, in part, a consequence of neotenization. Also implicated in the breakdown of this behavioral system is human provision of food, which relaxes (1) the behavioral consequences of injuries sustained in fighting and (2) the selective advantage enjoyed by group-hunting species who have evolved social systems of population regulation.

\section{INTRODUCTION}

In May of 1980, four 11-day-old ( $\pm 24 \mathrm{~h}$ ) Eastern timber wolf pups $(C$. lupus lycaon), one male and one female from each of 2 litters, were acquired from the Carlos Avery Game Park, Forest Lake, Minnesota, and fostered on a mature female wolf approximately 67 days after ovulation. The pups were housed in a $5.8 \times 3.7 \mathrm{~m}$ barn with access to a paddock and furnished with a $1.8 \times 1.2 \mathrm{~m}$ insulated den box. Because it is difficult to socialize wolf pups who interact with adult wolves, the pups spent approximately $12 \mathrm{~h}$ per day with the authors. Most of the daytime contact with the pups was during and after bottle-feeding, with which we supplemented the foster mother's milk production until the pups were completely weaned at about 6 weeks of age. In addition, sleep schedules were rotated and staggered, so that each pup spent one night with each experimenter followed by 2 nights with the foster mother and so that no 2 pups spent consecutive nights together. 
In May of 1981, we fostered four 10-day-old ( $\pm 48 \mathrm{~h}$ ) Alaskan Malamute pups, one male and one female, from each of 2 litters, on the same female wolf. The pups were introduced to the foster mother approximately 77 days after ovulation and were housed in the same facility, permitted contact with the same adult members of the animal colony, fed the same diet, administered the same experimental tests, and, in general, subjected to the same regimen as the wolf pups, with 3 exceptions. Although the female wolf lactated with equal abundance during both seasons of foster motherhood, the Malamutes weaned themselves more abruptly than the wolves and therefore made an earlier transition to solid food. Second, they did not require the same rigorous socialization program as the wolf pups and therefore did not spend 2 nights in 3 sleeping with humans. Third, they were allowed somewhat more frequent access to the outdoor enclosure.

\section{COMPARATIVE SOCIAL DEVELOPMENT}

Since the information-processing experiments for which the pups were acquired did not begin until they were 6 weeks old, this period was used for developmental observations which were continued until $S s$ were approximately 9 months old. Comparing behavioral and physical development in litters of wolf and dog pups is by no means an original enterprise, but in most earlier studies (e.g. Zimen, 1972; Bakarich, 1979), the pups were reared entirely by hand. Thus, both wolves and dogs were reared under conditions that are "natural" only to domestic dogs. To what extent this may have differentially affected behavioral development in the two congenors is not known, but the possibility of such confounding cannot be overlooked, since Bakarich (1979) found that the shift from maternal rearing to hand rearing did differentially affect wolf and dog physical development. Immediately after removal from the mother, the wolves exhibited a temporary decline in growth rate, which was not observed in the dogs. In the present study, all $S s$ spent part of the day under conditions typically experienced by wolf pups born in captivity and part of the day under conditions typically experienced by domestic dog pups.

The following paragraphs summarize the major developmental differences recorded in the experimenters' laboratory notebook. It must be emphasized that these observations are based on a small sample and that only one domestic dog breed is represented. Furthermore, apart from the actual ages at which specific developmental events were observed, much of the material is necessarily impressionistic.

Since social interaction and other forms of behavior may depend on physical attributes, e.g. sensory discrimination or motor coordination, the section begins with a discussion of the differences observed in physical development. 


\section{Physical conformation and development}

One reason that Malamutes were selected as the breed to be compared with wolves in the information processing study is that they are among the so-called "lupine" breeds, that is, dogs that in the course of domestication have retained their wolf-like size and general morphology (Mech, 1970). This is, however, true only of the adult Malamute. In comparison to the wolf pup, the Malamute pup is extraordinarily fetalized. Indeed, the cephalocaudal proportions of the Malamute neonate are so pronounced (at least to observers who have reared only wolf pups) that the pups were submitted to repeated veterinary examinations on the suspicion that they suffered from hydrocephalism, chondrodysplasia, or both.

Along with limb and body proportions, locomotor skills also developed more rapidly in the wolves than in the Malamutes. By 19 days of age, for example, the wolf pups were able to climb over the $45 \mathrm{~cm}$ sidewalls of the pen to which they were confined when sleeping with one of the experimenters. By 32 days of age, in contrast, the Malamute pups had yet to surmount the $15 \mathrm{~cm}$ barrier that was placed across the den-box door to keep bedding material from spilling out. When the wolf pups were administered Scott and Fuller's (1965) adaptation of Kohler's (1927) barrier test (Frank and Frank, 1982a) at 6 weeks of age, their motor performance was already comparable to that of mature, small dogs. The Malamutes, including one pup who had only recently begun to walk more than 3 or 4 steps at a time, waddled around the barriers like so many fuzzy, animated soccer balls. That they were so easy to catch was the major reason that the Malamute pups were permitted greater access to the half-acre forest enclosure. By 6 weeks of age, the wolf pups were fast and nimble enough to avoid us, and capture was often dependent on the intercession of the foster mother. By 10 weeks of age, however, such differences had almost disappeared. In fact, the best time recorded by any pup through the 6-unit maze (Scott and Fuller, 1965, pp. 232-238) that was administered in Ss' 11th and 12th weeks was posted by the same Malamute who could barely walk at 6 weeks of age. He negotiated the serpentine course at a full run, which required him to "change lead" at every choice-point like a well trained gymkhana horse.

Mean weights for both groups were plotted against age, and unlike Bakarich (1979), we found no temporary plateau in the wolf pups' rate of growth. Both groups exhibited smooth, exponential gains. The curves were colinear for the first 5 weeks, with wolves averaging approximately one pound more than the Malamutes, but at 35 days of age the Malamutes began to gain weight more rapidly, and by 49 days of age were heavier than the wolves.

Nor did we find as much difference in deciduous dentition as did Bakarich. By 16 days, deciduous teeth had irrupted in all wolves, and by 19 days of age the same was true for the Malamutes. 


\section{Canalization of neonatal feeding}

Conventional wisdom holds that since wild animals are more instinctbound than domestic animals their behavioral development is less susceptible to environmental perturbation. Were this true of reproductive and maternal behavior, of course, zoos would not have to import giraffes, gorillas, pandas, and the like. Accordingly, other researchers who had handreared litters of wolf pups counseled us to feed ours with a stomach tube, but since we wanted them to nurse on the foster mother, we chose the more painstaking chore of introducing them to the bottle. We had bottle-reared the foster mother and so already had a varied selection of bottles, feeders, and nipples, and by trial and error eventually discovered a combination that the pups found acceptable. Nor did their demands become any less exacting after they began bottle feeding. Feeding and digestion were easily disrupted by any number of things, a minor change in formulation, use of a slightly stiffer or slightly more pliable nipple, a barely discernable deviation in temperature, etc. Likewise, although the wolf pups initiated their own weaning by rejecting (or biting) the nipple, the transition to a meat and kibble mix was a slow process, beginning with a mixture that was mostly bottle formula and, over a period of weeks, reducing the quantity of formula and adding ground kibble. The Malamute pups not only took to the bottle immediately but were oblivious to all but the most extreme variations (e.g. soured formula) and made the transition to solid food in three days.

\section{Social partner preference}

Despite the number of hours we spent in daily contact with the wolf pups, their socialization to humans was always tenuous. From about 6 weeks of age to about 8 weeks of age, their orientation toward humans shifted from passive acceptance to indifference to tolerance to wariness, and even during their most acceptant period they showed an unequivocal preference for canine social partners. At 2 weeks of age, the pups would huddle behind the foster mother when either of us approached the den box, and as soon as they were old enough to leave the barn they showed a similar preference for the other adult members of the colony, a male Malamute and a male wolf-Malamute hybrid. In this connection, we have reported elsewhere (Frank and Frank, 1982a) that for some of the problem-solving tasks in which interaction with familiar humans has been used as positive reinforcement for domestic dogs (see Scott and Fuller, 1965, p. 20), we substituted interaction with an adult dog when testing wolf pups.

As soon as they developed sufficient locomotor ability to express their social preferences in the form of approach behavior, Malamutes exhibited precisely the opposite orientation. Within a day or so of opening their eyes, for example, they would abandon the foster mother and crowd around the den-box door when they detected our approach to the barn. By the time 
they were completely weaned ( 4 weeks of age), they had become much more socially independent of the foster mother than was ever true of the wolf pups. They remained decidedly amiable toward her and actually enticed her into more frequent play than did the wolves, but their greetings and other forms of active submission were more subdued and perfunctory, less deferential, and, since they were ordinarily performed only after periods of separation, less frequent. The intense, effusive and prolonged "greeting frenzy" was reserved largely for humans. Submissiveness toward the male canids persisted somewhat longer. It must be noted, however, that although the pups were in daily contact with the males from 2 weeks of age, the pups initiated no interaction until 41 days of age (as compared with 21 days for the wolf pups). Furthermore, the males spent much of the hot summer in the house and probably acquired much the same novelty value as working fathers of pre-school children. Finally, both males tended to rebuff the pups' social overtures, which may also have contributed to continued solicitousness.

\section{Activity level and transactions with the environment}

One of the first behavioral differences recorded in the laboratory notes was the Malamutes' lower activity level. During their first 5-6 weeks, the Malamute pups slept more hours, were less easily wakened, and exhibited longer sleep and activity cycles than the wolves. In their third week, for example, wolf pups sleeping with the experimenters were active for approximately 30 minutes for every 2 hours they slept. The Malamutes at the same age slept 6-7 hours without interruption. The wolf pups' higher level of activity was reflected both in their transactions with the physical environment and in social interaction. The actual number of hours engaged with social and physical objects was not recorded for either group, but the absolute number of notebook entries recorded for both types of behavior suggests that during their first 4 months, wolves spent a greater proportion of their waking hours investigating their physical environment, manipulating, dragging, chewing, shaking, shredding or carrying objects, than did the Malamutes. This conclusion is consistent with comparative expenditures during the summers of 1980 and 1981 for chew-toys and food bowls, replacement of furniture, repairs on the compound, and landscaping. It is also consistent with formal observations recorded during testing. In the first 2 days of the barrier test, for example, $S s$ were brought into the test arena, given a small helping of food and allowed several minutes to explore the arena (Frank and Frank, 1982a). The wolf pups showed only moderate interest in the food but quartered every square foot of the arena. The Malamutes devoured the food and confined their subsequent investigations to the vicinity immediately surrounding the food dish.

In the area of social activity, one of the most striking differences was the Malamutes' later appearance and slower development of complex conspecific interaction. For the first 3-4 weeks, the Malamute pups' principle form of 
social activity (apart from brief episodes of intense fighting) was what developmental psychologists call "parallel play". The wolf pups, by 4 weeks of age, had already exhibited a number of activities involving true social reciprocity, wrestling, mutual licking, tug-of-war, and rudimentary dominance display. However, the notes suggest that the proportion of waking hours spent in social interaction declined in the wolf pups after about 8 weeks of age, whereas it steadily increased among the Malamute pups through their first 4 months. Toward the end of their first summer, the wolf pups also exhibited a noticeable increase in social distance. When sleeping, for example, the wolves by about 5 months of age tended to arrange themselves in either widely separated pairs or scattered throughout the enclosure. The Malamutes tended to sleep, along with the adults, clustered within a $15-\mathrm{m}$ radius of the main gate, except on very hot days when each sought out the coolest place he could find to scratch out a sleeping depression (cf. Zimen, 1978/1981, pp. 30-31).

It is difficult to compare developmental changes in the wolves' and Malamutes' levels of social interaction with adult members of the colony, because management considerations required that the wolves be allowed less access to the main enclosure and therefore less opportunity for such interaction. Nevertheless, it is our impression that, apart from their continued intense attachment to the foster mother, the wolf pups became somewhat more socially independent of the adult canids by about 5 months of age than did the Malamute pups from humans.

\section{Aggression and agonistic play}

One of our more surprising observations was that the Malamutes exhibited earlier and more intense aggression than did the wolves and were much older than the wolf pups when agonistic play first appeared. We distinguish agonistic "play" by four criteria: (1) it is more frequently initiated by "obtrusive" approach behavior (Schenkel, 1967) than by expressions of dominance; (2) dominant and subordinate roles alternate rapidly and apparently by mutual consent; (3) both participants are easily distracted, which breaks off the interaction; (4) there is a general air of relaxation, i.e. lack of tension in body postures, no indication of high autonomic arousal, etc. (cf. Zimen, 1978/1981, p. 184). Such behavior was apparent in the wolf pups by 2 weeks of age, but serious fighting was observed for only a brief period between 4 and 6 weeks of age. Erich Klinghammer (1980, personal communication) tells us that this is unusual, and we suspect that it resulted from our practice of feeding the pups separately, which eliminated competition for food resources or feeding priorities (however, see Zimen, 1978/ 1981 , pp. 80-85). Alternatively, it is possible that the absence of juvenile wolves and relatively infrequent contact with aloof adult male canids favored the early establishment of better defined and more stable social rankings than is generally observed in wolf pups, thereby reducing the frequency and 
intensity of aggressive interaction. In contrast, the Malamute pups exhibited unrestrained fighting from about 2 weeks of age, and we suspect that injury was avoided only because they lacked the powerful jaw musculature that was already evident in the wolf pups and because, unlike the wolf pups, the Malamutes were born with a heavy winter coat and subcutaneous fat layer. The laboratory notes also record at least 2 instances of a Malamute pup launching a full-blown attack on the foster mother, once when she tried to suppress 2 pups who were fighting, and once when she merely crowded a pup who was trying to squeeze past her to leave the home barn. At no time was any wolf pup ever seen attacking an adult member of the colony.

Agonistic play did not appear in the Malamute pups until 4-5 weeks of age and seemed to correspond with the development of running skills that permitted bouts of chase behavior.

\section{Behavioral and physical sexual dimorphism}

One difference that frankly relies largely on subjective or aesthetic impression is that the dogs exhibited a substantially greater degree of physical sexual dimorphism than did the wolves. The females appeared to us to be more "delicate", "finer boned", "more feminine". No such differences were noted in the wolves. The only empirical support for this claim is that naive observers could not reliably distinguish the female wolves from the males but could generally identify the male and female in each littermate-pair among the Malamutes. Furthermore, the male from each Malamute litter weighed more than his female littermate; the same was not true for the wolf pups. That body weight is sex-related in dog pups but not wolf pups is also reported by Zimen (1978/1981, p. 84).

There were also sex-related social behavior differences in the Malamutes that were not apparent in the wolves. The females tended to be more submissive, less socially assertive (e.g. less demanding of attention from humans), and less willing to defend toys, food, and so forth. Furthermore, we have some evidence that the Malamutes exhibited cross-sexual social partner preferences among the adult animals, which was not true of the wolf pups. In a note comparing social and food reinforcement in wolves (Frank and Frank, 1982c), it is reported that the wolf pups at 10 weeks of age ran the 6-unit maze significantly faster when the reinforcement was a minute or two of interaction with one of the adult males than when the reinforcement was a tablespoon or two of canned fish. Although the Malamute pups showed a slight preference for food, the difference was not significant. However, if the Malamute sample is separated by sex, the male pups favored the food and the females the interaction with the adult male dog $(t=3.33, \mathrm{df}=2$, $0.025<P<0.05$ ). 


\section{Cleanliness and fastidiousness}

Finally, we observed one difference that may be scientifically trivial, but which has important implications for management and husbandry. Unlike the wolf pups, the Malamutes exhibited an apparently innate aversion to feces, both their own and those deposited by the adult members of the colony. After the 15-cm barrier was removed from the den box at 32 days, we did not find a single scat in the den box. Indeed, except for 2 occations, all feces were found in the paddock, which was the furthest point removed from the den box. Likewise, when the Malamutes were given free access to the outdoor enclosure, the only feces found in any part of the barn were those produced by the foster mother, and in the outdoor enclosure the Malamute pups, despite their slower development of motor coordination, exhibited a remarkable ability to avoid stepping in feces.

\section{NEOTENIZATION: SELECTION FOR PROLONGATION OF JUVENILE ATTRIBUTES}

Insofar as the differences reported above are consequences of the domestication process, they might be attributed to several mechanisms. The canalization of neonatal feeding behavior, for example, would seem to be a rather straightforward adaptation to coexistence with humans. Those specimens in whom reproductive and maintenance behavior were disrupted by the artificial and highly variable conditions inherent in the human environment were simply lost to the gene pool thousands of years ago. For animals like dogs, who live in intimate contact with humans, equally direct pressures should favor selection for cleanliness. Furthermore, since dogs generally live in more closely confined circumstances than wolves, disease pathogens transmitted in fecal matter would constitute a selection pressure on dogs that wolves have never encountered. It is possible, however, that cleanliness is more highly developed in the Malamute than in other breeds. Unlike most working dogs (e.g. sheep-guarding breeds and sheep-herding breeds), Malamute pups were traditionally reared indoors by the Mahlemiut Indians who domesticated them and, according to 19 th century accounts, allowed them to sleep in cook pots and food bowls (Riddle and Seeley, 1976). Clearly, the less continent specimens were likely to be turned out at an earlier age than more fastidious individuals, and in the harsh arctic environment were therefore likely to live shorter lives and contribute fewer of their genes to the next generation.

In an earlier paper, however (Frank, 1980), the first author suggested that important differences in wolf and dog information processing might be attributed to the more comprehensive process of neotenization, selection for prolongation of juvenile attributes. It is possible that neotenization is likcwise responsible for many of the differences reported above. The most definitive feature of the domestication process is that man inserts himself 
between the animal and its environment. This disruption of the natural order has probably exerted its greatest impact on species in which human interference extends to early care and maintenance. In this connection, a number of writers (e.g. Gould, 1979) have documented the emotional effects on humans of neotenic features in animals. Animals (or drawings of animals) are perceived as "cuter", more "cuddly", and more "lovable" to the extent that they possess such features. It is therefore reasonable to surmise that animals in which juvenile behavior and morphology persist would receive more attention and more prolonged nurturance than would precocious individuals and would therefore stand a better chance of both survival and longevity. This is not only a matter of better care, earlier detection of injury or illness made likely by more extensive contact, and more solicitous treatment during periods of recuperation. We might also suppose that a longer period of dependence establishes in the human caretaker a stronger affectional bond and thus reduces the likelihood that the animal will be abandoned, eaten, destroyed, or turned out to fend for itself when circumstances might otherwise call for such action. Two observations are pertinent to this argument. When the wolf pups were 5 weeks old, one of our colleagues was invited to bring his wife and 2 pre-teenage daughters to meet them. The young girls bottle-fed the pups dutifully but with no remarkable enthusiasm, while the parents looked on with an air of fond detachment. A year later the same family was likewise invited to meet the Malamute pups. On this occasion the behavior was quite different. The pups were cleaned, coddled, cuddled, cosseted, carried about the house and generally made much of. Even the girls' mother was caught up in this orgy of maternalistic indulgence. More noteworthy, however, is that the foster-mother wolf was also more nurturant with the Malamute pups than with the wolf pups. She washed them earlier and more frequently, spent 2-3 times as many hours in the den-box with them as she did with the wolf pups, was more defensive toward intruders, showed far more distress when one was missing (e.g. during supplemental feedings), played with them and continues to play with them for longer periods of time.

Under such selection pressures, it is hardly surprising that the Malamutes exhibited more fetalized neonatal body proportions and slower development of adult proportions, slower locomotor development and development of motor coordination, and protracted peer interaction and dependence on dominant (human) adults. In a sense, man has created the domestic pup in the image of an idealized infant. Two of the most frequent complaints one hears from mothers of infants is that they wake up frequently during the night and that they are "fussy" eaters. It is surely no coincidence that the so-called "terrible twos" begin just about the time that a child becomes mobile, exploratory and therefore capable of "getting in trouble". As indicated above, the same "undesirable" attributes were observed in our wolves but not our Malamutes. Just as the puppy has been cast in the mould of an idealized infant, so is the idealized child the standard to which 
we have shaped the adult dog. One such prevailing ideal is the Boy Scout, who is enjoined to be trustworthy, loyal, helpful, friendly, courteous, kind, obedient, cheerful, thrifty, brave, clean and reverent. With the exception of "reverent" and "kind" (and allowing synonyms for "courteous" and "thrifty") all of these descriptors are to be found in the breed standards published by the American Kennel Club (AKC, 1968). Given the recent volume of material published by developmental and social psychologists on the pervasiveness of early sex-role training in children, we suspect that the greater sexual dimorphism observed in Malamutes is also a consequence of this anthro-paedomorphism. To the extent that Scott and Fuller (1965, p. 28) are correct in their assessment that "a dog is not a four-legged and childish human being dressed up in a fur coat," it is not for lack of mankind's efforts.

\section{RITUALIZED AGGRESSION AND DOMINANCE ORDERING}

Although neotenization is generally associated with slower or later appearance of characteristics, it may paradoxically have contributed to the earlier and less restrained aggression that was observed in the Malamute pups. Konrad Lorenz (1966) is generally credited with popularizing the proposition that natural selection operates against intragroup aggression in lethally equipped social animals. Especially in predators, who must rely on speed and endurance to obtain food, any injury is likely to reduce an individual's lifetime reproductive potential and, therefore, his contribution to the species' gene pool. The effects of intragroup strife on mortality, morbidity, and, consequently, reproduction are particularly evident in the African lion (Schaller, 1972), and in some non-predatory species aggression per se, apart from injury, can be detrimental to genetic survival. In the North American bison, for example, the breeding season itself places so high a demand on a bull's caloric reserves that additional energy expended on prolonged or frequent combat will significantly reduce his reproductive fitness (Lott, 1972).

Such selection pressures notwithstanding, qualities such an tenacity, strength, endurance, and pain-tolerance, which may contribute to success in agonistic conflicts, are also instrumental in predation and in competition with other species, as well as alien conspecifics, for food and other vital resources. Even within the group, aggression becomes an important factor when food is scarce and viability of the social unit may require uneven distribution of resources. With these antagonistic selection pressures operating simultaneously, we should expect evolution to favor both preservation of aggressive behavior and the concurrent development of systems that inhibit indiscriminant aggression within the group. Indeed we find that in the present stage of evolution, social animals who are lethally equipped with horns, claws or teeth frequently exhibit complex ritualization of agonistic behavior.

In the wolf this ritual, which was first documented in 1947 by Rudolph 
Schenkel (cited in Mech, 1970), involves a graduated series of "challenges" and responses, beginning with interactions that may appear innocuous or even inconsequential (such as one wolf staring fixedly at another or resting his chin across the other's back), and progressing through such obviously aggressive expressions as vertical lip retraction, growling, snarling and snapping. Such agonistic displays are an important factor in the establishment and maintenance of a social order in which one male (sometimes called the alpha male) dominates all other members of the pack, the beta male all but the alpha male, and so forth. Females also have a dominance order, headed by the alpha female who is usually (but not always; see Woolpy, 1968) subordinate to all mature males. It should be emphasized, however, that social rank is not strictly ordinal. Status relationships among subdominant adults are seldom well defined, and even among dominant individuals are complicated by mate preferences, filial and sibling allegiances (Rabb et al., 1967; Fox, 1973; Lockwood, 1979), seasonal variation in general activity level (Zimen, 1975) possibly occasioned by fluctuations in food resources or hormonal changes associated with the breeding cycle, and by specific events that may confer a temporary or object-related dominance, e.g. possession of food or the birth of pups (Mech, 1970; Fox, 1972).

\section{Ontogeny of dominance behavior in wolves}

Traditional ethologists (e.g. Tinbergen, 1951; Eibl-Eibesfeldt, 1975) argue that, in general, agonistic displays are fixed action patterns, responses to highly specific cues that can be elicited in more or less complete form with no prior learning at the same stage of development in all like-sexed members of a particular species. Likewise, Mayr (1974) argues that dominance and submission behaviors in the wolf, like most forms of intraspecific signalling, are governed by closed behavioral programs. This position is consistent with our observation that some components of this behavioral system appear almost as soon as wolf pups open their eyes. In an earlier paper, the first author (Frank, 1980) reported eliciting a threat bark in a 16-day-old pup by intruding his hand into its "ownership zone", and in the 1980 litter we observed dominance mounting at 13 days of age and tail erection and postural expressions of dominance by 19 days.

The early appearance of these behaviors notwithstanding, additional observations suggest that experience plays an essential role in the development of agonistic expression. First, the assumption that ritualized aggression is innate would imply not only contextually appropriate behavioral expression, but also correct response to such expression. On the contrary, our wolf pups remained totally oblivious to threats from adults long after they were perfectly able to express threat themselves. Although both active and passive submission behaviors were initiated quite early (in the course of greeting, food-begging, play and the like), our notes do not record a single observation of submission behavior in response to assertion of dominance or intimidation 
until the pups were more than 3 months old. About that time, we noticed what seemed to be gratuitous suppression of the pups by the foster mother. Since her behavior eventually focussed on one particular pup, and since the other pups eagerly joined in this harassment, we wondered at first if she was creating a "scapegoat" or omega wolf. It soon became evident, however, that her target was simply the most obtrusive of the pups (who eventually emerged as the undisputed "little alpha" of the litter). We have no quantitative evidence that agonislic activity per se was more frequent immediately following these episodes than at other times, but we did note that subsequent play and other social activity took on an aggressive or contentious character that persisted for up to an hour after the foster mother retired from the scene. Although serious fighting was actually less frequent than in early summer, expressions of dominance, intimidation and threat became more fully elaborated and articulated with submission behavior in the course of these interactions.

Development of these behaviors took a somewhat different course, however, in the foster-mother wolf, who was taken from her litter at $12 \mathrm{~h}$ of age and hand-reared in a rather unnatural social group comprised of humans, one dog and one wolf-dog hybrid. Although the dog romped with her frequently in her first 3 months, we observed virtually no agonistic play in their interactions and the hybrid generally tried to avoid any interaction with the young wolf at all. Consequently, we had observed considerable submission behavior in her (both toward us and toward the canids), but only fragments of what could be called dominance behavior (as opposed to generalized arousal) solely by virtue of its social context. However, when she was 3 months old, the dominant, and heretofore very aloof, hybrid began to behave with unaccustomed submissiveness. When the female pup approached in greeting he responded for several days by pawing solicitously and then rolling over on his back. Initially this seemed to puzzle her and she hung back, as wolves so often do when confronted with something new. However, after a day or so she became bold enough to make a quick rush and seize his tail, for which she received a growl and a snap. She retreated, but only momentarily; on her second rush she seized a rear leg and was again "punished". The sequence repeated itself several times, until she gripped him by the neck. This time he became immediately immobile and then gently disengaged by pushing her away with his paw. In very short order she responded to his recumbent "submission" by seizing, or at least mouthing, his throat or neck for 4 or 5 seconds and then allowing herself to be pushed away. Following this "lesson", agonistic play became more frequent, but because of the composition of the group there was no occasion for conflict until her first estrus, at which time her agonistic behavioral repertoire appeared fully developed.

From these observations, it seems likely that even though the components of agonistic expression may be innate, organization of these components into a coherent behavioral system involves a complex interplay of 
maturation and social interaction (especially with peers; see Zimen, 1978/ 1981 , pp. 60-64) and is probably mediated by some sort of "innate teaching mechanism" (Lorenz, 1969) comparable to the "learning template" that governs acquisition of the white-crowned sparrow's song (Marler, 1970) or the "learned instinct" by which the honeybee reprograms its flightplan after each excursion from the hive (Gould, 1975).

\section{The effects of domestication on dominance behavior}

When wolf and neolithic man first entered into their social contract, it is doubtful that either realized how long it would remain binding or the changes it would wreak on the four-footed party. Had someone shown him a Chihauhua or a cockapoo, the wolf might have had second thoughts, but if the domesticated wolf has suffered certain indignities, at least he has not had to rely entirely on his own skills and fitness for food. Consequently, even a seriously injured dog can live out his appointed span. In the process of domestication, therefore, selection pressures against aggression have relaxed, and in most breeds of dog the wolf's highly predictable dominance ritual has disintegrated into an assortment of independent behavioral fragments. Fox (1971), for example, points out that facial expressions of threat and greeting are often difficult to distinguish in dog and that dogs, unlike wild canids, may bite without warning. ${ }^{1}$ Nor, conversely, is the dog's warning a reliable predictor of attack (Fox, 1965). His submission responses have likewise lost much of their adaptive function and, consequently, their behavioral integrity and social significance; a domestic dog on his back is more probably soliciting attention than initiating submission or responding to domination. Scott and Fuller (1965) have similarly noted that some of the wolf's agonistic behaviors are absent in the dog, and suggest that this results from selective breeding to accentuate or inhibit certain agonistic components. However, their discussion of selective breeding actually focusses on behavior involved in interspecific conflict, namely predation, rather than intraspecific conflict. It would therefore seem more parsimonious to entertain the same explanation by which they account for the observation that pup-care behavior is "less well developed" (i.e. fragmented) in male dogs than in male wolves. Just as human intervention in the rearing of domestic pups has relaxed selection pressures favoring paternal caretaking behavior, so have human restraint of aggression in domestic dogs and provision of food relaxed selection pressures favoring the ritualization of aggression observed in wild canids (Fox, 1969).

\footnotetext{
${ }^{1}$ The extent to which intragroup aggression is ritualized in wild canids is often overstated. Zimen (1978/1981, pp. $60 \mathrm{ff})$ points out that (1) the biting inhibition is absolute only with respect to pups, (2) serious attacks are seldom preceded or accompanied by growls, lip retraction or other expressions of intimidation or threat, (3) passive submission will not ordinarily foreclose such an attack (cf. Schenkel, 1967, pp. 327-328).
} 
As indicated at the beginning of this section, it is likely that neotenization has also contributed to the disintegration of this behavioral system. In his discussion of felid predatory development, Leyhausen (1965) observes that the various behavioral elements that culminate in the killing nape-bite (lying in wait, stalking, pouncing and seizing) appear and are perfected very early in development but are not linked into an ordered sequence until "the dominant appetence toward killing " matures and the cat has experienced a few kills. The interaction he describes between innate and experiential factors is very similar to that which we have proposed in the development of agonistic behavior in the wolf. The role of maturation is especially important, because it implies that a neotenized species of cat would possess all of the behavioral components of predation, but they would not become organized into a coherent and predictable sequence. This is precisely the situation with agonistic expression in the domestic dog.

Schenkel (1967) points out that submission is a social role and that satisfaction of the motivation underlying submissive expression "depends on the response of the superior partner" (p. 324). The inability of our adult Malamute to comprehend this interplay of dominance and submission behaviors has been a source of constant tension in our group. When the hybrid was about 6 months old, for example, he began to challenge the dog. He would usually begin with play attacks when the dog was asleep. Unlike male wolves, who give obstreperous pups ample cease-and-desist warnings (Fox, 1971), the Malamute generally ignored these preliminary sorties completely. Consequently, the hybrid would invariably escalate until he provoked a full-blown attack, which both dominated and appeared to confuse the pup. The same thing occurred when we introduced our first wolf, a 7-month-old female, to the dog and hybrid. After deferring to the hybrid (who responded with perfectly appropriate dominance behavior even though he had had no contact with lupine animals since he was removed from the litter at 5 weeks of age), she approached the Malamute and repeated her submission behaviors. When he did not react (cf. Mech, 1970, p. 81), she performed the entire sequence again. Failing once more to elicit a response, her approach became more obtrusive. The Malamute continued to ignore her until she nipped his cheek, at which point he grabbed her by the scruff and threw her several yards through the air. 'The wolf and dog never did learn to communicate, and only the conscientious intervention of the hybrid (who assumed dominant status in the group the day the wolf deferred to him) prevented them from ever seriously injuring one another. Not all of the Malamute's communicative failures ended in conflict, however; sometimes the results were comical. One of the male wolf pups formed an especially strong attachment to the old dog and tried to subordinate himself at every opportunity. Lacking any cooperation from the dog, this sometimes forced him into contortions that became more absurd as he grew older and taller. At about 5 months of age, he was trying eagerly to elicit some response to 
his submission behaviors when the Malamute yawned. The pup managed to thrust his entire head in the dog's mouth, and when the dog found his jaws clamped around a wolf pup, he appeared as astonished as the pup was delighted.

At one time we speculated that the Malamute's inability to meter his aggression was a consequence of insufficient interaction with his own littermates. He was acquired at 5 weeks of age, which in our present litter was just about the time that agonistic play began. As indicated above, however, we have observed the same sort of explosive, all-or-nothing aggression in the Malamute pups, and are therefore inclined to attribute the earlier observations to prolongation of juvenile behavior. Unlike the older Malamute, however, the Malamute pups seem to be learning to orchestrate dominance and submission behaviors. The foster-mother wolf is practicing the same "scapegoating" on them as she did with the wolf pups, and we suspect that their conformity reflects their capacity for "forced training", which we have discussed elsewhere (Frank and Frank, 1982b).

\section{Dominance, reproduction and domestication}

A fundamental tenet of Wynne-Edwards' (1962) theory of animal social behavior is that systems of social organization evolve because they serve to optimize the balance between organisms and their vital resources. In wolves, dominance ordering functions to regulate reproduction so that packs seldom exceed 15 or 20 individuals even in captive populations, where food supplies are, in effect, unlimited (Zimen, 1978/1981). The social and reproductive life of the wolves at the Chicago Zoo (Brookfield, Illinois) has been studied since 1958, and the role of dominance ordering in the pack's reproductive history (1961-1965) is discussed in detail by Rabb et al. (1967). These and more recent observations on the same pack yield several important points.

(1) From October until the mating season begins in February there is an increase in aggressive encounters. This is a "sorting-out" period, during which the dominance hierarchy becomes well defined.

(2) During the breeding season, the dominance order established in the preceding months plays a major role in limiting reproduction in the pack. Courtship activity in subdominant males is suppressed by threat and intimidation from the alpha male. Likewise, such activity is suppressed in subdominant females by threat and even more serious aggression from the alpha female.

(3) Alpha status may be incompatible with reproduction. From 1961 to 1967 , the beta male was the most reproductively active male in the Chicago Zoo, and from 1969 to 1974 the annual litter was almost invariably produced by the beta male and beta female.

(4) Reproduction is also limited by persistent mate preferences. Records 
of courtship activity suggest that a female establishes a sexual preference for the male who was in the alpha position when she reached sexual maturity. Early data (Rabb et al., 1967) suggested that male preferences were also related to dominance structure, but subsequent observations (M. Rabb, 1977, personal communication) indicate that males establish a preference for their own mothers, irrespective of rank.

Points (3) and (4) are not entirely consistent with Zimen's (1978/1981) observations, and the Rabbs are presently replicating their observations on a new pack in which the parent generation includes a larger number of agemates than was the case in their original population. Furthermore, results from long-term studies of the relationship between dominance structure and reproduction of captive wolves in The Netherlands, the German Democratic Republic and Canada are soon to be published, so it would be unnecessarily premature to propose a model based on the Chicago data. If, however, these points are confirmed by other investigators, the ecological implications are interesting. First, since female wolves prefer older consorts (Woolpy, 1968; Fox, 1973) the alpha male will probably not sire pups until his own mother dies (cf. Zimen's 1976, 1978/1981 postulation of an innate incest barrier), at which time he will have his choice among the females who came to maturity during his tenure. When mortality rates are low, this will function to increase the spacing of litters, and when mortality is high it guarantees the pack a reservoir of litter-bearing potential. Second, during periods of low mortality, fewer pups are required to maintain pack size, and the reproductively inactive alpha male can devote more of his time to excrcising his dominance in the suppression of reproduction among subdominant wolves than he could if involved in reproduction himself. Finally, if it is generally true that beta animals are former alpha animals (This was the case in Chicago from 1969 to 1974, but Zimen reports that deposed alpha animals are either ejected from the pack, leave the pack voluntarily, or are relegated to subdominant status.), genetic components of the tendency to dominance are not lost to the pack as a result of the alpha male's reproductive inactivity.

In free-ranging wolves, reproduction and regulation of numbers are complicated by fluctuations in food supply and by the possibility of both emigration and immigration. Zimen $(1976,1978 / 81)$ advances a comprehensive feedback model of the factors that influence pack and population size in wolves undisturbed by human incursion. The distal variable is food supply, which is determined both by the number of available prey animals and the size of the typical prey specimen. The proximal variables are mortality, voluntary emigration, enforced emigration, immigration, and natality. These two sets of variables, however, are mediated by a variety of social structural variables, primarily age, sex, and social rank, which govern the pattern of aggressive interactions, and seasonality which affects the overall level of aggression in the group.

(1) Mortality. Mortality within the pack is primarily among pups, who have higher nutritional requirements than adults and are thus more debilitated when food is scarce. 
(2) Voluntary emigration. Voluntary emigration is most common among low-ranking adults and juveniles.

(3) Forced emigration. Because serious aggression is more frequent among females than among males, forced emigration is highest among low-ranking females.

(4) Immigration. Acceptance of adult immigrants is rare in well-established packs, and less frequent in large than in small packs. It is most commonly a factor in packs that are being established by animals who have been forced out of other packs.

(5) Natality. Few packs produce more than one litter of pups per year, and this litter is most often born by the alpha female. In packs that include more than one sexually mature female, this is not a matter of biological infertility (Packard, 1980), but of social suppression of subdominant females' sexual behavior by the alpha female. Furthermore, pups of subdominant females who do breed are less likely to survive than pups of dominant females, possibly owing to rank-dependent access to kills. Finally, in times of food scarcity, there is some evidence (Mech, 1975) that litters include a disproportionate number of male pups.

Although dominance ordering clearly limits reproduction in larger wolf packs, Zimen (1978/1981) points out that smaller packs ordinarily include only one sexually mature female. In such circumstances, dominance ordering contributes to population regulation by governing dispersion rather than mating; as they reach sexual maturity, younger animals may be driven off (this is especially likely for females) or leave voluntarily, since their low-priority access to food may frequently compel them to forage independently, thereby reducing their social contact with and attachment to the pack. Unless such dispersers are accepted into another pack or can establish new packs, they are unlikely to reproduce.

Insofar as dominance ordering in canids confers a selective advantage by virtue of its role in population regulation, it remains advantageous only for group-hunting species. With the advent of domestication, of course, the modern dog's forebear ceased to be a group hunter, and this too has undoubtly contributed to the breakdown of ritualization in the dog's agonistic behavior.

\section{ACKNOWLEDGEMENTS}

This research project was supported in part by grants from the Faculty Development Fund of the University of Michigan-Flint and from the Office of the Vice President for Research.

This paper is dedicated to C.C. who, in his gentle wisdom, understood Lorenz better than any of us. 


\section{REFERENCES}

American Kennel Club, 1968. The Complete Dog Book (revised edn.). Doubleday, New York.

Bakarich, A.C., 1979. Comparative development in wolves (Canis lupus) and dogs (Canis familiaris). Unpublished Masters Thesis, Trinity University, San Antonio, Texas.

Eibl-Eibesfeldt, I., 1975. Ethology, The Biology of Behavior (2nd edn.). Holt, Rinehart and Winston, New York.

Fox, M.W. 1965. Canine Behavior. Charles W. Thomas, Springfield, IL.

Fox, M.W. 1969. The anatomy of aggression and its ritualization in canidae: A developmental and comparative study. Behavior, $35: 242-258$.

Fox, M.W., 1971. Behaviour of Wolves, Dogs, and Related Canids. Harper and Row, New York.

Fox, M.W., 1972. Socioecological implications of individual differences in wolf litters: A developmental and evolutionary perspective. Behavior, 45: 298-313.

Fox, M.W. 1973. Social dynamics of three captive wolf packs. Behavior, 47: 290-301.

Frank, H., 1980. Evolution of canine information processing under conditions of natural and artificial selection. Z. Tierpsychol., 53: 389-399.

Frank, H. and Frank, M.G., 1982a. Comparison of problem-solving performance in sixweek-old wolves and dogs. Anim. Behav., 30: 95-98.

Frank, H. and Frank, M.G., 1982b. Comparison of forced training performance in sevenweek-old wolves and dogs. In preparation.

Frank, M.G. and Frank, H., 1982c. Food reinforcement vs. social reinforcement in timber wolf pups. In preparation.

Gould, J.L., 1975. Do honeybees know what they are doing? Nat. Hist., 88(6): 66-75.

Gould, S.J., 1979. Mickey Mouse meets Konrad Lorenz. Nat. Hist., 88(5): 30, 32, 34, 36.

Kohler, W., 1927. The Mentality of Apes (2nd edn.). (E. Winter, trans.) Routledge and Kegan Paul, London (originally published in 1925).

Leyhausen, P., 1965. On the function of the relative hierarchy of moods (as exemplified by the phylogenetic and ontogenetic development of prey-catching in carnivores).

Z. Tierpsychol., 22: 412-494.

Lockwood, R., 1979. Dominance in wolves: Useful construct or bad habit. In: E. Klinghammer (Editor), The Behavior and Ecology of Wolves. Garland STPM Press, New York.

Lorenz, K.Z., 1966. On Aggression. Ilarcourt, Brace, World, New York.

Lorenz, K.Z., 1969. Innate bases of learning. In: K. Pribram (Editor), On the Biology of Learning. Harcourt, Brace, Jovanovich, New York.

Lott, D.F., 1972. Bison would rather breed than fight. Nat. Hist, 81(7): 40-45.

Marler, P., 1970. Birdsong and speech development: could there be parallels? Am. Sci., 58: $669-673$.

Mayr, E., 1974. Behavior programs and evolutionary strategies. Am. Sci., 62: 650-659.

Mech, L.D., 1970. The Wolf: The Behavior and Ecology of an Endangered Species. Natural History Press, New York.

Mech, L.D., 1975. Disproportionate sex ratios in wolf cubs. J. Wildl. Manage., 39: 737740.

Packard, J.M., 1980. Deferred reproduction in wolves (Canis lupus). Unpublished Doctoral Dissertation. University of Minnesota.

Rabb et al., 1967. Social relationships in a group of captive wolves. Am. Zool., 7: 305311.

Riddle, M. and Seeley, E.B., 1976. The Complete Alaskan Malamute. Howell Book House, New York.

Schaller, G.B., 1972. The Serengeti Lion: A Study in Prey-Predator Relations. The University of Chicago Press, Chicago. 
Schenkel, R., 1967. Submission: Its features and functions in the wolf and dog. Am. Zool., 7: 319-329.

Scott, J.P. and Fuller, J.L., 1965. Genetics and the Social Behavior of the Dog. University of Chicago Press, Chicago.

Tinbergen, N., 1951. The Study of Instinct. Oxford University Press, New York.

Woolpy, J.H., 1968. The social organization of wolves. Nat. Hist., 77(5): 46-55.

Wynne-Edwards, V.C., 1962. Animal Dispersion in Relation to Social Behaviour. Oliver and Boyd, London.

Zimen, E., 1972. Wölfe und Königspudel: Vergleichende Verhaltensheobachtungen, Piper-Verlag, Munich.

Zimen, E., 1975. Social dynamics of the wolf pack. In: M.W. Fox (Editor), The Wild Canids. Van Nostrand, New York.

Zimen, E., 1976. On the regulation of pack size in wolves. Z. Tierpsychol., 40: 300-341.

Zimen, E., 1981. The Wolf: A Species in Danger (trans. E. Mosbacher). Delacorte, New York (originally published in 1978). 